\title{
Noise levels in Madrid: association with emergency hospital admissions.
}

J. Díaz ${ }^{1}$ R. García ${ }^{2}$, A. Tobías ${ }^{3}$, J.C. Alberdi ${ }^{1}$, C. López ${ }^{1}$ E. Hernández ${ }^{2}$, G. Maqueda ${ }^{2}$, A. Jordán ${ }^{1}$, A. Otero ${ }^{1}$.

${ }^{I}$ Centro Universitario de Salud Pública, Madrid, Spain

${ }^{2}$ Departamento Fisica de la Tierra II, Facultad de Fisicas, Universidad Complutense de Madrid, Madrid, Spain

${ }^{3}$ Hospital de la Santa Creu i Sant Pau. Servicio de Epidemiología Clínica y Salud Pública, Barcelona, Spain

\section{Abstract}

Previous studies have evaluated the influence of meteorological variables and chemical pollutants on mortality and morbidity recorded on cities. In comparison, little attention has been paid to the role of environmental noise as risk factor in urban environments. The aim of this paper is to describe noise values in Madrid and evaluate its effect on emergency admissions. Cluster analysis is used to identify spatial patterns, spectral analysis is applied to investigate time characteristics. Box-Jenkins models are used to evaluate crosscorrelation between the number of admissions and the rest of the variables. Those representing acoustic pollution, meteorological conditions and air pollution have been considered as model inputs. Noise levels in Madrid are extremely high; during night the recorded values are above limits for $100 \%$ of the cases, during the day values above limits range between 73.7 and $99.6 \%$, depending on the considered measuring station. Two clusters have been identified in the city, with different noise levels. Annual and weekly cycles are the most relevant noise time features. Diurnal noise is the most significant external variable for emergency admissions, followed by atmospheric pollutants and temperature. Noise levels in Madrid are unacceptable high, traffic and leisure activities explain the spatial and time distribution of noise across the city. The association noise-emergency admissions is strong and does not show 
seasonality, suggesting that noise must be considered when evaluating the health effect of urban environments. Traffic appears to be the major environmental risk factor in Madrid.

\section{Introduction.}

When studying the influence of urban environment on human health, much attention has been paid to the effect produced by air pollutants of chemical origin $[1,2]$ or atmospheric conditions [3,4]. Different methodologies have been applied to evidence such effects: Box-Jenkins modeling [5,6,7], Poisson regression [8], or general linear models [9]. All these studies come to a common conclusion, valid for most urban environments: air pollution has a measurable impact on mortality and morbidity, even when the pollutant concentrations are under the health standards. Additionally, a changing pattern has been detected for air pollution in many cities, with decreasing values of pollutants emitted by industrial or domestic sources, such as $\mathrm{SO}_{2}$ or particulate matter, and increasing values for those associated to traffic, such as ozone or $\mathrm{NO}_{\mathrm{x}}[7]$.

In the past little attention has been paid to the role played by environmental noise in the morbidity levels of the cities, however, in the last decade an increasing number of studies are focusing on the role of environmental noise on health $[10,11]$. They evidence that the noise effects are auditory and nonauditory, and that people's response may be influenced by social status $[12,13]$. According to the Cooperation and Economic Development Organization (CEDO), more than 130 million people suffer from exposure to noise levels above $65 \mathrm{~dB}$ (A) [14], and, for most of them, the levels exceed the limits established by WHO [15] or EPA [16]. Particularly, Spain is one of the noisiest countries in the world, CEDO has estimated that $74 \%$ of the Spanish population is exposed to unacceptably high noise levels [17].

Health problems associated to high noise levels include physiological alterations of the hearing system, which can lead to a progressive and nonconscious loss of hearing $[18,19]$. Non-hearing effects associated to environmental noise have also been detected in the last years. They include psychic disorders, associated with higher suicide attempts [20-24] and digestive pathologies [25] in adults and children [26]. Cardiovascular diseases also seem to be associated to noise levels. It has also been established that noise can be considered as a risk factor for arterial hypertension [17,27-31]. Such relationship was established even for moderate noisy environments, as those produced by city traffic [32].

One of the main problems when trying to evaluate the role of environmental noise on health is the scarcity of proper measurements of noise levels adequately representing the real exposure to noise [11]. This has lead to a lack of studies including environmental noise levels as input for the behavior of health variables.

Most of these previous studies, even those centered in the role played by traffic $[27,33]$, do not control the synergic effect which can be originated by air 
pollutants of chemical origin, thus leading to uncertainties when assessing the noise attributable effects.

The aim of this paper is to provide a description of the noise levels recorded in Madrid and to evaluate its association with emergency admissions, controlling the confounding effect produced by other environmental variables such as air pollutants concentrations and weather.

\section{Methodology}

The time period used in this study was 1-1-1995 to 31-12-1997, when the acoustic pollution measurements were available on a routinary and homogeneous basis. Four kinds of variables have been used.

- Acoustic pollution variables. A real-time acoustic pollution network with 6 station is operated in the city. Diurnal equivalent Level, (Leqd) (including the 08-22h period), Night equivalent level, (Leqn) (including the $22-08 \mathrm{~h}$ period) have been considered for every single station and for the average of the whole 6 stations. Total daily values for the $24 \mathrm{~h}$ period (Leqt), have also been considered. Average values for the six stations, denoted as Leqda and Leqna have also been considered. Data were provided by the Madrid City Council Noise Pollution Measurement Network.

- Meteorological variables: maximum daily temperature (T) and relative humidity $(\mathrm{rH})$ at $07 \mathrm{~h}$. They have been chosen because in previous studies [7] they exhibited the strongest relationship with the emergency visits in Madrid. The reference observatory was Madrid-Retiro, located in the city, close to the reference hospital. Data were provided by the Spanish National Institute of Meteorology.

- Air pollution variables. The air pollution measurement network includes 24 stations distributed across the city. Daily averages from: SO2, PST, NOx, NO2 and $\mathrm{O} 3$ have been considered. Data were provided by Madrid City Council Air Pollution Network.

- Emergency admission. The number of daily emergency inpatients in the Hospital General Universitario 'Gregorio Marañón' has been considered as indicator of the emergencies in the whole city [7]. They include daily nonprogrammed in-patients for all the causes included in the ICD-9 codes except traumatisms and births.

Usual descriptive methods have been applied to noise levels to obtain a complete picture of the noise pollution within the city. Normality analysis was performed on every variable included in the study. Deterministic components (trends and seasonalities) were estimated through Fast Fourier Transform [34], the non-deterministic (autoregressive and moving average) ones through BoxJenkins modeling.

In previous papers [5,7], a V-relationship between temperature and emergency in-patients was established, with a minimum daily emergency admissions or comfort value of $30.8{ }^{\circ} \mathrm{C}$. To control the temperature effect, two additional variables were used,

$\mathrm{Tc}=30.8^{\circ} \mathrm{C}-\mathrm{T}$, if $\mathrm{T}<30.8^{\circ} \mathrm{C}$ 
$\mathrm{Th}=\mathrm{T}-30.8^{\circ} \mathrm{C}$, if $\mathrm{T}>30.8^{\circ} \mathrm{C}$.

A quadratic relationship with ozone had also been detected previously [7], with a minimum value of $45 \mu \mathrm{g} / \mathrm{m} 3$, thus additional variables were considered.

$\mathrm{O} 3 \mathrm{~h}=03-45 \mu \mathrm{g} / \mathrm{m} 3$, if [O3] $>45 \mu \mathrm{g} / \mathrm{m} 3$

$\mathrm{O} 3 \mathrm{l}=45 \mu \mathrm{g} / \mathrm{m} 3-\mathrm{O} 3$, if [O3] $<45 \mu \mathrm{g} / \mathrm{m} 3$.

Analysis of scatter-plots obtained in previous papers $[6,7]$ recommended the use of a $\log$ transformation for SO2 before entering the models. The rest of the variables have been used without any previous transformation.

A cluster analysis was performed to investigate the spatial distribution of noise levels across the city. Classical spectral techniques have been applied to evaluate periodicities and trends in the time series [34].

To investigate the relationship noise level- daily emergency admissions scatterplots were drawn. To quantify the effect of theses variables above the $65 \mathrm{~dB}(\mathrm{~A})$ level established by WHO [14], Leq 65 values have been computed for day, night and total (Leqd65, Leqn65, Leqt65).

A Box-Jenkins approach [35] has been used to evaluate those variables having a bigger impact on the daily emergency admissions. Thus, a prewhitening procedure has been used to eliminate spurious effects associated to common seasonalities and trend patterns. With this aim, ARIMA models were built for every series, using simple autocorrelation (ACF) and partial autocorrelation (PACF) functions as identification tools. Models goodness-of fit- were measured through the Box-Ljung Portmanteau test [35] and the restriction of white noise structure imposed on the residuals $\mathrm{ACF}$ and PACF. Once the series were prewhitened, cross-correlation functions (CCF) were computed in order to evaluate significant values and lags according to a t-test.

A Box-Jenkins model with exogenous inputs [35] was used to describe the behavior of the daily emergency admissions variable in terms of the rest of the considered variables. AR, MA and trend terms have been included. Annual, semestral and quarterly seasonalities were introduced as sine and cosine functions of 365,180 and 90 days periods respectively. The effect of the seasonal cycle was included through a qualitative variable ranging from 1 (for Sunday) to 7 (for Saturday). Meteorological, air pollution and noise variables were introduced in the model as exogenous inputs lagged according to the significant values detected in the prewhitened CCFs.

Additionally, influenza effects have also been controlled through a dicotomic variable (g1), with a value of 1 when influenza epidemy is declared and 0 for the rest of the days. Data for the epidemic days were provided by the Public Health Department of Madrid Regional Government.

A step-by-step modeling procedure was followed since the exogenous inputs exhibited high collineality and we wanted to evidence the role of the noise variables unambiguously. First an univariate model for the daily emergency admissions was obtained, controlling trends and seasonalities. Next the noise was included to evidence its overall influence on daily emergency admissions. Then, meteorological and pollution variables were added to the univariate model. A final model including the three types of exogenous variables was then produced. This procedure has allowed a better comparison of every model performance in 
terms of the residual variance, and a better identification of every variable contribution to the model.

Since most of the considered variables exhibited a high seasonality, three periods have been chosen to evaluate the models: the whole year, winter period (from October to March, both included) and summer period, including the rest of the months. The statistical analysis was performed with SPSS windows package (release 7.5)

\section{Results}

\subsection{Noise levels}

Six stations have been considered to evaluate the noise levels in Madrid. The recorded values are very high The situation seems worst during the night that during the day, since the range for night values is $61.7-69.4 \mathrm{~dB}$ (A), which means that night average values can be up to $14.4 \mathrm{~dB}(\mathrm{~A})$ above the limits. For Leqd, the range of the average values of the 6 stations is $65.2-70.5 \mathrm{~dB}$ (A). When examining the histograms (figures not shown) it can be seen, that during Leqn values are above the limit in $100 \%$ of the cases. For Leqd values, the percentage varies from $73.7 \%$, for station 1 to $99.6 \%$ for station 2 . Those figures make Madrid a city with unacceptable high noise levels and one of the noisiest in the world.

To investigate the spatial distribution of the noise levels, a hierarchical cluster analysis has been performed, using as variables daily recorded values for every station. For Leqd values, two clusters can be identified; the first one corresponds to the lowest levels and includes stations 1 and 3 (cluster average is $65.5 \mathrm{~dB}$ (A) \pm 2.0 . Cluster 2 includes the rest of the stations, with average value $69.3 \mathrm{~dB}$ (A) \pm 2.1 For Leqn values, there is no clear identifiable pattern. These spatial patterns are coherent with the traffic distribution in the city.

Spectral analysis (spectrum not shown) reveals that no trend is detected and a significant 7-days period. The average evolution along the week for Leqd values follows a common pattern, with rather constant figures from Monday to Friday and lower values during the weekends. This decrease is maximum for Sundays and ranges between 5.4 and $1.9 \mathrm{~dB}(\mathrm{~A})$, depending on the stations. However, the evolution of the Leqn values is not uniform

\subsection{Noise and emergency admissions.}

To evaluate the noise-admissions relationship prewhitened CCFs were computed between the daily number of admissions on one side and Leqd, Leqn and Leqt for every single station, every cluster centroid and the global average of the six stations. It can be seen that lag zero values are significant, the strongest relationship being that for Leqa, thus being this variable the one included in the models representing noise levels. 
Table 1 summarizes the step-by-step modeling results, after following the procedure described in the previous paragraph, for organic causes.

It can be seen that the univariate model explains $52 \%$ of the total variance of the daily admissions. As a first step, Leqda 65 was entered. It improves the model, increasing the explained variance in $4.3 \%$. Next, meteorological variables were entered, $T_{h}$ and $T_{c}$ being the only significant ones. However, their role is very poor, with an increase of $0.7 \%$, only. When chemical pollutants are included, only $\mathrm{NO}_{x}$ and $\mathrm{O}_{3}$ are significant, and they increase the model performance in $3.1 \%$ of explained variance. When all the external inputs are included, the model reaches its better performance, with an increase of $7.2 \%$ in the explained variance. The significant variables are noise, $\mathrm{T}_{\mathrm{h}}, \mathrm{NO}_{\mathrm{x}}$ and $\mathrm{O}_{3}$.

It can be seen that noise is the exogenous variable explaining a higher variance percentage, even higher than that attributed to the pollutants. From a quantitative point of view, it can be seen, that every decibel above $65 \mathrm{~dB}(\mathrm{~A})$, has an associated increase of 3.3 cases in the number of admissions, which represents around $5 \%$ of the total. This is highly important when considering that $94 \%$ of the days, $65 \mathrm{~dB}(\mathrm{~A})$ values are surpassed in the city. In the modeling results for the two seasons previously defined, it can be seen that noise effects exhibit low seasonality, since it is significant in both cases with similar coefficients. $\mathrm{NO}_{\mathrm{x}}$ is also significant for winter and summer, $\mathrm{O}_{3}$, exhibits, as expected high seasonality, being significant only for summers, when high concentration values are recorded.

\section{Discussion and conclusions}

Madrid is a city with an unacceptable high background noise level, which is above the limits during $100 \%$ of the night periods, and $97 \%$ of the diurnal periods. Two different areas can be identified in the city, according to the noise level, with differences between them of $4 \mathrm{~dB}$ (A). Such difference can be attributed to the traffic pattern, since those stations recording higher levels are located in areas with heavier traffic. Time distribution is rather uniform across the city, with day/night differences of around $4 \mathrm{~dB}(\mathrm{~A})$, and higher values during diurnal period of weekdays. Weekend night values are uniform across the city, with higher values in the leisure areas, even higher than those of the weekdays nights are. Monthly values show a different pattern depending on considering Leqd or Leqn. The explanation for such a difference during day and night is attributable to the fact that July and August are holiday periods, which makes traffic less heavy, and noise levels lower. However, July nights are still very busy in the city, with an increase of leisure activities, making that during July nights, noise levels are similar to those of the rest of the year. August is the month with lower business and leisure activity, with most of the people out of the city, which explains the minimum for both Leqn and Leqd values. 
Transactions on Biomedicine and Health vol 5, (c) 2001 WIT Press, www.witpress.com, ISSN 1743-3525

Environmental Health Risk 209

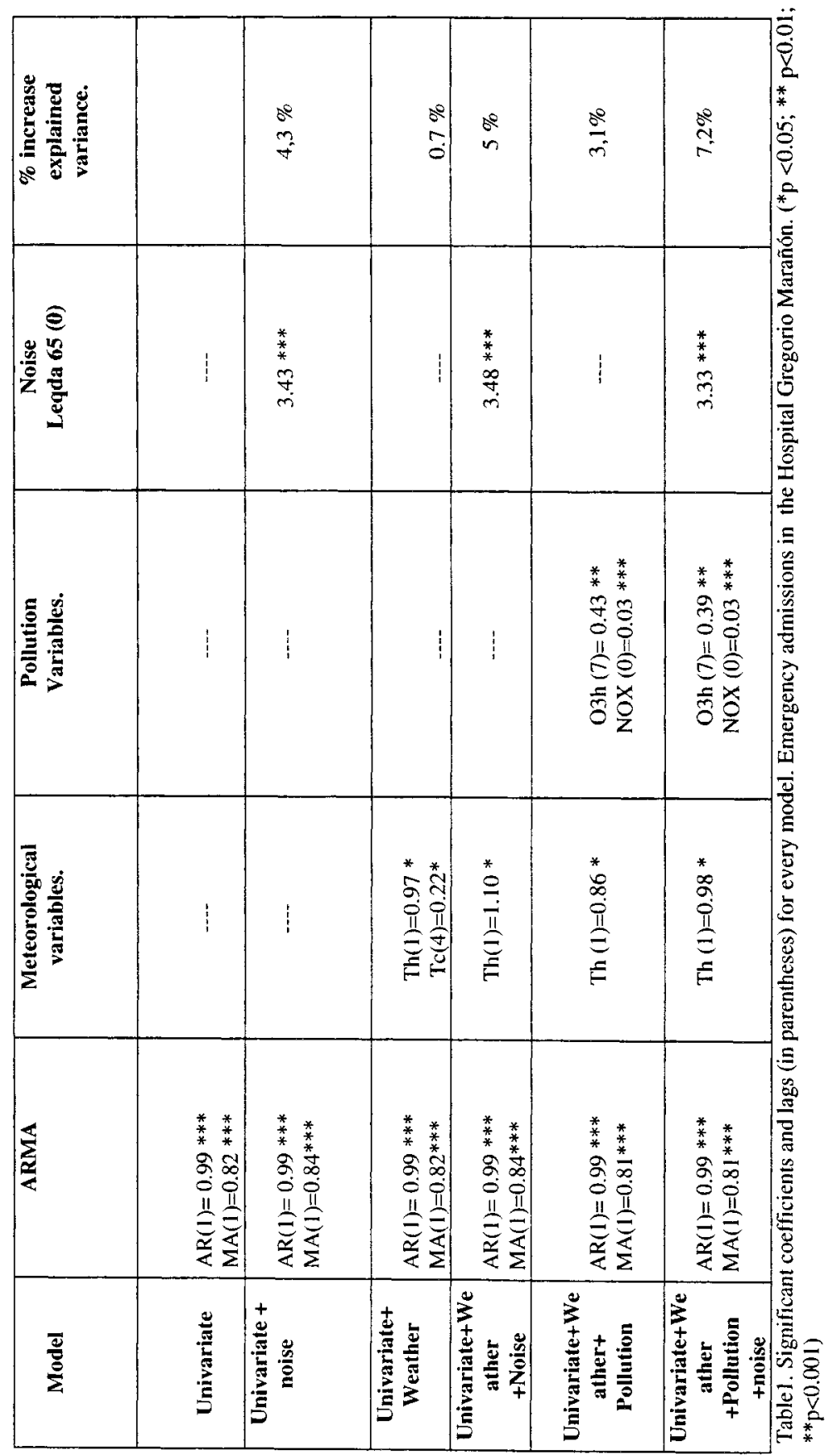


It must be emphasized that the global average is the best indicator, even better that the stations close to the city hospital. This can be attributed to the fact that the population move across the whole city, exposed to a combination of noise levels, no individual station is capable of representing such value, while the average captures much of this information.

Leqn values do not become significant in the model, they are above the limit for $100 \%$ of the cases, but their absolute values do not seem to produce relevant effects on the population .

Thus, we can conclude that Madrid's population can be globally considered at risk from noise exposure, which can be globally represented by the diurnal average values across the whole city.

The time series models evidence a clear association between noise and the number of daily emergency admissions. As has been mentioned in the introduction, physiological effects have been previously detected, as a result of environmental noise exposure [13], our results suggest that the noise effect can induce acute episodes of those pathologies related to noise. However, one must be cautious with this interpretation, since there are not similar results for industrial noisy environments, where the detected acute effects are mostly related to the hearing system. More detailed studies, beyond the scope of this paper, should be carried out to ellucidate the nature of this connection. However, it must be emphasized that the methodology used in this study should prevent the detection of spurious correlations and that there is a plausible association mechanism for this effects.

Two major remarks can be made about the role of the chemical pollutants. First, it must be noticed that only, $\mathrm{O}_{3}$ and $\mathrm{NO}_{x}$ are significant, in comparison with previous studies in Madrid [6,7]. This can be attributed that pollutants related to domestic and industrial sources, such as $\mathrm{SO}_{2}$ and particulate matter exhibit a decreasing trend in the last years due to different emission reduction policies implemented in the city [36]. However those pollutants related to traffic are increasing, especially $\mathrm{O}_{3}$, which presents a growing number of summer episodes.

Secondly, noise explains more variance than any of the chemical pollutants measured in the city, explaining more variance than the global contribution of both, $\mathrm{O}_{3}$ and $\mathrm{NOx}$. Thus, we think that noise should be considered as input variable when modeling the effect of urban environments on human health.

Finally, it must be emphasized that traffic appears to be the main environmental risk factor for health in Madrid, since it is the major common source of those significant pollutants (noise included)of the model. Thus, environmental health in Madrid should be addressed to a reduction of traffic levels and their impact. 


\section{Acknowledgements}

This study was supported by a grant from the Madrid Regional Authority Board of Education and Culture as part of Project 08.7/0004/98 Health Sciences Coordinated Action Program.

\section{References}

[1] Quenel P, Medina S, Pirard P, Momas I, Le Moullec Y, Festy B, Dab W. Health service base morbidity indicators as a measure of health effects or air pollution. Eur J Public Health 4:201-206,1994.

[2] Schwartz J . Air pollution and daily mortlity: a review and meta-analysis. Environ Research 64 :36-52,1994.

[3] Kalstein LS, Greene JS . An evaluation of climate/mortality relationships in large U.S. cities and the possible impacts of a climate change. Environ Helth Perspectives. $105: 84-93,1997$.

[4] Samet J, Zeger S, Kelsall J, Kalkstein LS. Does weather confound or modify the association of particullate air pollution with mortality? An analysis of the Philadelphia data, 1973-1980. Environ Research.77 :9$19,1998$.

[5] Alberdi JC, Díaz J, Montero JC, Mirón IJ. Daily mortality in Madrid Community 1986-1992 :relationship with meteorological variables. Eur J Epidemiol 14:571-578,1998.

[6] Alberdi JC, Díaz J, Montero JC, Mirón IJ, Pajares MS. Air pollution and mortality in Madrid (Spain) : a time series analysis. Int Arch Occup Environ Health $71: 543-549,1998$.

[7] Díaz J, García R, Ribera P, Alberdi JC, Hernández E, Pajares MS, Otero A Modelling of air pollution and its relationship with mortlity and morbidity in Madrid, Spain. Int Arch Occup Environ Health 72: 366-376,1999.

[8] Katsouyanni K, Schwartz J, Spix C, Touloumi G, Zmirou D, Zanobetti A, et al .Short term effects of air pollution on health : a European Approach using epidemiologic time series data: the APHEA protocol. $J$ Epidemiol Com Health 50 :S12-S18.,1996.

[9] Schwartz J . Non-parametric smoothing in the analysis of air pollution and respiratory illness. Can J Stat $4: 471-487,1994$.

[10] Forum : Loud-but Not Yet Clear. Environ Health Perspect 106 :A222A223,1998.

[11] Passchier-Vermeer W, Paschier W. Environ Health Perspect 106-11: Correspondence, 1998.

[12] Health Council of the Netherlands: Commitee on Noise and Health. Noise and Health. $\mathrm{Nr}$ 1994/15E. The Hague :Health Council of The Netherlands, 1994.

[13] Institute for Environmental Health. The Non-auditory Effects of Noise. Leicester, UK: Institute for Environmental Health, 1997.

[14] Organisation de Cooperation et de Dévelopment Economiques. Les politiques de lutte contre le bruit. Paris, 1980. 
[15] Organisation Mondiale de la Sante. Critères d'hygiène de l'environment12. Le bruit. Geneve:O.M.S. 1980.

[16] Noise Control Act of 1972. USA Public Law 92-574, 92 ${ }^{\text {nd }}$ Congress, HR11021, Oct.1972.

[17] Agencia de Medio Ambiente .El ruido como problema ambiental. Madrid,1991.

[18] Brookhouser PE; Worthington DW; Kelly WJ. Noise-induced hearing loss in children. Laryngoscope.102: 645-55,1992.

[19] Zaborski L; Taniewski M; Krechniak. A Application of regression analysis to examination of degree of loss of hearing. Bull-Inst-Marit-Trop-MedGdynia. 47: 85-92,1996.

[20] Muzet A. Les effets du bruit sur le sommeil. C-R-Seances-Soc-Biol-Fil. 83: 437-442,1989.

[21] Sieira-Ferrin C; Castineira FJ; Minones-Trillo J; Moreno-Garcia F. Aproximacion al estudio del ruido ambiental y sus consecuencias en Santiago de Compostela. Rev-Sanid-Hig-Publica-Madr. 62: 1317 1327,1988 .

[22] Smith A. A review of the effects of noise on human performance.Scand-JPsychol.30: 185-206,1989.

[23] Stansfeld S, Gallacher WB, Shipley M. Road traffic noise and psychiatric disorder:prospective findings from Caerphilly study. $B M J ; 313: 266$ $267,1996$.

[24] Staples SL. Human response to environmental noise. Psychological research and public policy. Am-Psychol. 51: 143-150,1996.

[25] Tomei F; Tomao E; Papaleo B; Baccolo T.P; Alfi P. Study of some cardiovascular parameters after chronic exposure to noise. Int $J$ Cardiol .33: 393-399,1991.

[26] Perego L; Bertoni G; Goglio F; Giovannelli G . Children and noise. Eur-JEpidemiol. 12: 549-50,1996.

[27] Babisch W; Ising H; Gallacher JEJ; Elwood P.C.. Trafic noise and cardiovascular risk. The Caerphilly study, first phase. Outdoor noise levels and risk factors. Arch Environ Health. 43:407-414,1988.

[28] Lang T; Fouriaud C; Jacquinet-Salord M.C.. Length of occupational noise exposure and blood pressure. Int Arch Occup Environ Health .63: 369$372,1992$.

[29] Tomei F; Papaleo B; Baccolo T.P; PersechinoB; Spano G; Rosati M. . Noise and gastric secretion. Am J Ind Med .26: 367-372,1994.

[30] Vacheron A. Le retentissement cardio-vasculaire du bruit. Bull. Acad. Natl. Med.173: 387-92,1992.

[31] Wu T.N; Chiang H.C; Huang J.T; Chang P.Y. Comparison of blood pressure in deaf-mute children and children with normal hearing: association between noise and blood pressure. Int Arch Occup Environ Health.65:119-123,1993.

[32] Kristensen TS. Cardiovascular diseases an the work environment: A critical review of the epidemiologic literature on nonchemical factors. Scand $J$ Work Environ Health .15:165-179, 1989. 
[33] Orlando P, Perdelli F, Cristina ML, Piromalli W. Environmental and personal monitoring of exposure to urban noise and community response. Eur J Epidemiol. 10:549-554,1994.

[34] Jenkins GM, Watts DG. Spectral analysis and its applicatios. Holden-Day, San Francisco, 1968.

[35] Makridakis S, Wheelwright SC, McGee VE. Forecasting methods and applications. Wiley and Sons. San Francisco, 1983.

[36] Consejería de Medio Ambiente y Desarrollo Regional. El Medio Ambiente en la Comunidad de Madrid de 1997 a 1998. Madrid, 1999. 